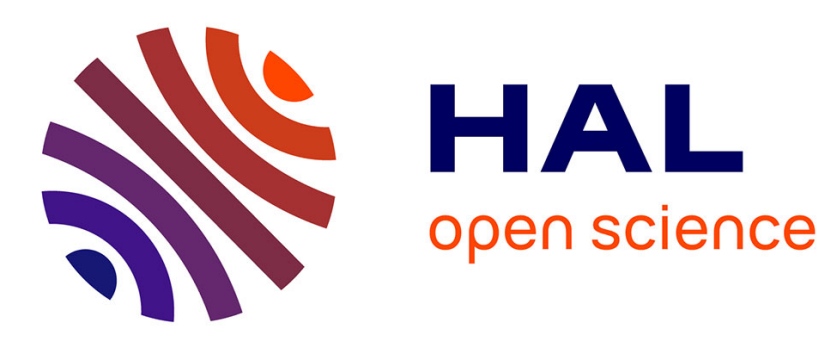

\title{
Causes and pathophysiology of malignant pleural mesothelioma
}

Didier Jean, Marie-Claude Jaurand

\section{To cite this version:}

Didier Jean, Marie-Claude Jaurand. Causes and pathophysiology of malignant pleural mesothelioma.

Lung Cancer Management, 2015, 4 (5), pp.219-229. 10.2217/lmt.15.21 . inserm-02483449

\section{HAL Id: inserm-02483449 https://www.hal.inserm.fr/inserm-02483449}

Submitted on 18 Feb 2020

HAL is a multi-disciplinary open access archive for the deposit and dissemination of scientific research documents, whether they are published or not. The documents may come from teaching and research institutions in France or abroad, or from public or private research centers.
L'archive ouverte pluridisciplinaire HAL, est destinée au dépôt et à la diffusion de documents scientifiques de niveau recherche, publiés ou non, émanant des établissements d'enseignement et de recherche français ou étrangers, des laboratoires publics ou privés. 


\section{Causes and pathophysiology of malignant pleural mesothelioma}

Didier Jean, Marie-Claude Jaurand

INSERM, UMR 1162, Institut Universitaire d'Hématologie (IUH), 27 rue Juliette Dodu, 75010 Paris, France

Université Paris Descartes, Labex Immuno-Oncology, Sorbonne Paris Cité, Faculté de Médecine, Paris, France.

Université Paris 13, Sorbonne Paris Cité, UFR SMBH, Bobigny, France.

Université Paris Diderot, Paris, France.

Keywords for indexing
1. Asbestos
2. Carbon nanotubes
3. Chromosome instability
4. DNA damage and repair
5. Fiber characteristics
6. Mesothelioma
7. Pleura
8. Signaling pathway
9. Thoracic tumor
10. Tumor suppressor genes 


\section{Summary points}

- Asbestos exposure is a major risk factor for MPM. Epidemiologic studies have not yet demonstrated a carcinogenic potential of SVFs in humans, but recent results point to an increased risk of MPM for subjects exposed to both asbestos and synthetic vitreous fibers. However, animal experiments have demonstrated that some SVFs can be carcinogenic.

- Inflammation and fiber uptake (phagocytosis) are early lung and pleural responses following exposure to asbestos fibers. Inflammation is sustained by the production of cytokines and growth factors by inflammatory cells. It may contribute to the development of cancer by the release of damaging and stimulating factors, oxidants and growth factors. Oxidants are also produced during phagocytosis and can be generated by the presence of redox reactions at the fiber surface.

- The action mechanism of asbestos fibers that accounts for their carcinogenicity-related potency involves the formation of chromosome abnormalities. These are the consequences of mitosis impairment, as demonstrated by the occurrence of micronuclei, chromosome missegregation, alteration of cytokinesis and centrosome duplication following asbestos treatment of mesothelial cells. These observations suggest that asbestos-treated mesothelial cells can undergo CIN, an important mechanism leading to genomic instability, a characteristic of cancer cells.

- Alterations in tumor suppressor genes are demonstrated in MPM. They concern BAP1, $C D K N 2 A, C D K N 2 B$ and $N F 2$. These genes play a major role in the control of different cell functions, including cell proliferation. So far, no oncogene has been identified in MPM.

- Neoplastic transformation is a long-term process in which cells undergo several genetic and physiological changes and modify their relationship with the cell microenvironment. Hypotheses concerning the action mechanism of asbestos fibers on mesothelial cells suggest that the six hallmarks of cancer could result from the action mechanism of asbestos fibers. Further results should more effectively identify the different steps leading to MPM. 
Abstract

Malignant pleural mesothelioma (MPM) results from the neoplastic transformation of pleural mesothelial cells. Asbestos exposure is a major risk factor for MPM, but epidemiologic studies demonstrated the occurrence of MPM in populations exposed to other fibers, and an excess of MPM in populations occupationally exposed to man-made vitreous fibers and previously to asbestos. The development of nanotechnologies also raises some concern about the potential health effects of new particles of high aspect ration, such as carbon nanotubes. Toxicological studies investigated the mechanism of asbestos-induced transformation of mesothelial cells, and molecular analyses defined the genomic and physio-pathological changes in MPM. These findings allowed identifying some key events accounting for the neoplastic process. This article summarizes the known and suspected causes of MPM, the cellular events and responses of mesothelial cells to asbestos fibers, and the alterations of key genes and regulatory pathways involved in the pathological mechanism. 


\section{Introduction}

Malignant pleural mesothelioma (MPM) results from the neoplastic transformation of mesothelial cells that cover the surface of parietal and visceral pleura. The medical and societal concern about this disease goes back to the 1960s with the publication of the association between asbestos exposure and malignant mesothelioma, as a result of the severity of the disease and the widespread industrial use of asbestos worldwide [1, 2]. This association has raised several questions concerning the interactions between mesothelial cells and asbestos, and the cellular response to asbestos, especially regarding the particulate nature of the fibers. More recently, the development of molecular tools has made it possible to begin to characterize genomic, genetic and epigenetic alterations in mesothelioma.

This article will summarize the known and suspected causes of MPM, the cellular events and responses of mesothelial cells to asbestos fibers, and the alterations of key genes and regulatory pathways involved in the pathological mechanism.

\section{Etiology of MPM}

Natural mineral fibers, asbestos and erionite

Past exposure to asbestos fibers represents the major risk factor for MPM and an etiological factor for other tumors such as lung cancer. Three main types of asbestos have been used in industry: chrysotile, crocidolite and amosite (Figure 1). Several intrinsic fiber parameters are important for inducing lung cancer and MPM. All types of asbestos fibers induce MPM. The "amphibole hypothesis" maintains that amphiboles are the most carcinogenic because of the presence of iron in their chemistry. Consequently, chrysotile was described to be less potent than amphiboles. However, while chrysotile does not contain iron, this element can be present in chrysotile samples as a contaminant [3].

Asbestos fibers induce benign pathologies such as pleural fibrosis (pleural plaques), a signature of past asbestos exposure. The link between fibrosis and cancer has not been established. However, in a recent paper, Pairon et al. (2013) found a statistically significant association between malignant mesothelioma and pleural plaques [4].

Erionite is a natural mineral that belongs to the family of zeolites (Figure 1). Like asbestos, erionite crystallizes as fibers. The relationship between erionite and MPM has been observed in Turkey where a high incidence of MPM has been reported in some geographic areas, and erionite is also present in its natural state in the USA [5]. Airborne erionite has been found elsewhere, e.g., in the state of North Dakota (USA) where the roads were surfaced with erionitecontaining gravel, but no epidemiological study has been performed. 
Man-made vitreous fibers (MMVF)

MMVF, or man-made mineral fibers, are synthetic, non-crystalline fibrous silicates. They encompass glass fibers (glass wool and continuous glass filaments), rock wool, slag wool and refractory ceramic fibers (Figure 1). They have been largely used as asbestos replacement materials in thermal and acoustical insulation. Refractory ceramic fibers have been developed for high-temperature applications.

Some types of MMVF were found to induce pleural mesotheliomas in toxicological experiments. Early epidemiological studies did not find an excess of mesotheliomas in populations occupationally exposed to MMVF but, in general, workers had also been previously exposed to asbestos. More recent studies have reported results in favor of an increased risk of MPM for subjects exposed to both asbestos and MMVF [6, 7]. Epidemiological studies showed the presence of unusual clusters of MPM cases in eastern Sicily (Italy), among inhabitants of the Biancavilla area. No asbestos was found in this area, but the presence of an amphibole mineral, fuoro-edenite, was detected. Fluoro-edenite displays two different morphological varieties, prismatic and fibrous. The widespread occurrence in amphibole fibers and the high incidence of MPM were correlated. The carcinogenic potency of this mineral was demonstrated following intra-peritoneal injection experiments with rats. The fibrous amphiboles from Biancavilla represent a case of environmental pollution from nonasbestos fibers. A similar situation was reported for the amphibole fibers from Libby, Montana (USA). These minerals are nonasbestiform varieties of amphibole minerals. They consist of crystalline elongated particles of prismatic morphology, and considered as "fiber-like". The detection of these fiber-like particles in air samples contributed to some discussions because the six asbestos minerals recognized by regulatory authorities are the fibrous serpentine mineral, chrysotile, and the amphibole minerals crocidolite, amosite, and the asbestiform varieties of the amphibole minerals tremolite, actinolite, and anthophyllite. Despite the mineralogical differences between these particles and asbestos, their ability to induce asbestosrelated diseases is a present concern.

\section{Carbon nanotubes (CNT)}

The possible health effects of nanoparticles (NP) are a current concern because they share some similar features with asbestos. CNT are NP with a cylindrical structure of graphene fibers. They have a diameter of less than $100 \mathrm{~nm}$, but are quite long and, as a result, are referred to as high aspect ratio (length/diameter) nanoparticles (HARNs). This is an important feature since the 
toxicity of asbestos depends on the size of these particles. CNT may contain metal impurities due the synthesis procedure. Similar to asbestos fibers, they show some genotoxicity and induce mesothelioma after injection in the peritoneal cavity of rodents. However, no data exists as of this time on a toxic potential in humans [8].

\section{Ionizing radiations}

The role of ionizing radiation has been suggested as a consequence of exposure to radiation for therapeutical purposes [9]. A recent study based on an analysis of US transuranium and uranium cancer registries reported an excess of malignant mesothelioma in workers in nuclear facilities, uranium mines and mills, as well as a manufacturing facility [10].

\section{Simian polyomavirus (SV40)}

DNA sequences of SV40 were found in several human tumors, probably due to the contamination of polio vaccines. SV40 represents a suggested cause of co-carcinogenicity with asbestos fibers. However, the presence of SV40 DNA sequences in malignant mesotheliomas is still open to debate [9].

\section{Genetic predisposition}

The question of genetic predisposition to pleural mesothelioma was addressed several years ago, with the discovery of familial cases of pleural mesothelioma. These cases were observed in relatives of workers occupationally exposed to asbestos fibers, but no specific gene was identified. Studies of polymorphisms in DNA repair genes or genes regulating the red-ox balance did not find a consensus as to candidate genes [11]. In a recent study, germline mutations in BAP1 (BRCA1-associated protein-1 gene), encoding a nuclear deubiquitinating enzyme, were found in two families with a high incidence of cancers, including mesothelioma, and somatic BAP1 mutations in mesothelioma cells were also found. These results show that $B A P 1$ is one of the candidate genes for mesothelioma predisposition [1].

\section{Lung and pleural cell responses to asbestos fibers}

Following inhalation, particles are deposited in the respiratory airways and in the lung where they are cleared or retained. Several studies have demonstrated that the fibers can be translocated to the pleura. On the one hand, asbestos fibers can be detected in the human pleura of patients with MPM by microscopic analyses. On the other hand, fibers are rapidly 
translocated in the pleural space after inhalation or intra-tracheal instillation, as demonstrated in animal experiments [12] (Figure 2).

Experimental studies in rodents showed that when the particles are deposited, an inflammatory reaction can occur in the lung and in the pleura. Once deposited, the fibers can be phagocytized by alveolar macrophages, but alveolar epithelial cells are also able to internalize asbestos fibers. The completion of fiber internalization is dependent on the fiber length. The so-called "frustrated phagocytosis" effect is related to the incomplete uptake of fibers due to their length that exceeds the macrophage dimensions. The mechanisms underlying asbestos fiber uptake are not completely understood. However, it was demonstrated that asbestos is phagocytized in lung epithelial and mesothelial cells according to an integrin receptor-mediated fiber uptake [3].

Free radicals and other reactive oxygen species (ROS) are potential DNA-damaging agents. The generation of ROS may occur via several mechanisms. Phagocytosis induces oxidative stress and intracellular oxidation in different cell types, including mesothelial cells. In parallel, an induction of DNA strand breakage, cell-cycle arrest and apoptosis occur. The blockade of phagocytosis by cytochalasin and integrin blockade decrease fiber uptake and its associated effects [2]. On the other hand, free radicals can be produced by alteration of the mitochondrial function of target cells and by reactions that occur at the surface of mineral dusts [3].

Asbestos fibers interact with cell plasma membranes and induce several signal pathways [13]. They appear to be a potent NLRP3 (Nod-like receptor protein 3) activator. NLRP3 is a member of the intracellular pattern recognition receptor family and is part of the inflammasome, a multiprotein complex containing caspase-1, which activates the proinflammatory cytokines interleukin (IL)-1 $\beta$ [14]. However, in a recent in vivo study using wild-type and NLRP3deficient mice exposed to asbestos fibers, it was found that NLRP3-deficient mice displayed an incidence of malignant mesothelioma and survival times similar to those of wild-type mice. These results suggest that early asbestos-induced inflammatory reactions are NLRP3dependent, but that NLRP3 is not critical in the chronic development of asbestos-induced mesothelioma [15].

Asbestos is a well-known genotoxic and mutagenic agent [2]. In vitro studies have investigated the effects of asbestos on mitosis in different cell types. Growth arrest, cytokinesis impairment, mitotic spindle alterations and loss of chromosome integrity have all been reported. It is noteworthy that mesothelial cells exposed to asbestos fibers exhibit both numerical and structural chromosomal alterations, as well as mitotic impairment (chromosome missegregation, micronuclei formation and centrosome duplication), which play a role in malignant mesothelioma development. Consequently, damage to the genetic material and 
chromosomal instability, an important long-term process of carcinogenesis, are induced by asbestos, independently of inflammation [2, 16, 17] (Figure 2). Asbestos has a genotoxic potential. It induces DNA damage (base hydroxylation, single strand and double strand breaks), micronuclei formation and chromosomal abnormalities. DNA damage has been demonstrated directly by DNA analysis in asbestos-exposed cells, and indirectly by the study of DNA repair. Poly(ADP-ribose) polymerase (PARP) is a nuclear zinc-finger protein with a function as a DNA damage sensor. In mesothelial cells, asbestos fibers produced a concentration-dependent PARP activation indicating the occurrence of DNA damage $[18,19]$. Moreover, in MPM, PARP was expressed but its activity level was low [20].

\section{Pathophysiology of MPM}

\section{Morphological features of MPM cells}

The histological classification of malignant mesothelioma includes three major types, epithelioid, sarcomatoid and biphasic (showing both epithelial and fibroblast-like mesothelioma cells). Both the epithelioid and sarcomatoid types can be subdivided into several subtypes [21]. The different phenotypes are associated with different prognoses. No extensive data on the physiological and molecular specificities of these different subtypes exist at this time.

Ultrastructural studies of MPM cells have been carried out. Nude mice injected with early passages of human mesothelioma cells in culture, obtained from different patients, showed typical mesothelial differentiation (long and slender microvilli, desmosomes, perinuclear intermediate filaments) in $50 \%$ of the cultures. Other cultures were poorly or not differentiated. Several cultured MPM cells exhibited features similar to the cells inside of the tumor; others were less well differentiated. Variability in ultrastructural differentiation may result from the culture microenvironment, but could also be related to the state of differentiation of the native tumor and to tumor cell heterogeneity, illustrating the plasticity of mesothelioma cells. MPM cells seem to retain characteristic biomarker expression profiles when they are maintained in culture [22].

Some efforts have been made to find a cytologic distinction between neoplastic mesothelioma cells and reactive mesothelial cells in effusions, but no immunohistochemical biomarker has been found. Recently, deletion at the 9p21 locus, a recurrent region of alteration in malignant mesothelioma, has been suggested as a good marker to distinguish between these cell types [23]. This finding should be confirmed by additional studies. 


\section{Genetic and epigenetic alterations in MPM}

Mutations in tumor suppressor genes have recently been reported in MPM. Early studies on gene mutations in MPM have reported frequent mutations in NF2 (neurofibromin 2), a gene encoding merlin, a multifunctional protein that links cytoskeletal components with proteins in the cell membrane. Frequent mutations have also been reported in genes located at the INK4 locus that encodes cell cycle regulator proteins, $\mathrm{P} 15^{\mathrm{INK} 4 \mathrm{~B}}\left(C D K N 2 B\right.$ gene) and $\mathrm{P} 16^{\mathrm{INK} 4 \mathrm{~A}}$ (CDKN2A gene), as well as P14 ${ }^{\mathrm{ARF}}$ (CDKN2A gene), a protein involved in the control of P53 stability. As mentioned above (section on the etiology of MPM), germline BAP1 mutations have been described in mesothelioma, but somatic mutations in this gene were also reported in mesotheliomas. $N F 2, C D K N 2 A / C D K N 2 B$ and $B A P 1$ genes are generally inactivated by deletion. TP53, a tumor suppressor gene altered in many types of cancers, exhibits a moderate frequency of alterations (about 10\%). No candidate oncogene has yet to be identified in malignant mesothelioma [24]. However, the first recurrent oncogenic mutation has been identified in the TERT promoter leading to an increase expression of telomerase and potentially involved in the maintenance of telomere length [25].

Concerning epigenetic alterations, MPM showed a specific DNA methylation profile and microRNA (miRNA) expression pattern. MiRNAs represent a family of small noncoding RNAs that negatively regulate gene expression by modulating target mRNA translation. They play a role as modulators of biologic processes. Abnormal miRNA expression has been reported in different types of cancers. MiRNA profiles have been studied in MPM using microarray approaches. Several miRNAs are abnormally expressed in MPM. They regulate cell cycle genes and genes involved in specific pathways such as epithelio-to-mesenchymal transition [26].

\section{Regulatory pathways altered in MPM}

Transcriptomic analyses of MPM tissues and cell lines have revealed that several pathways are deregulated in MPM. Alteration of the Hippo pathway was demonstrated in numerous studies since about 50 percent of MPM show a mutation of the $N F 2$ gene. Other studies have emphasized the role of receptor tyrosine kinase driven signaling, involving most of the growth factor receptors (VEGFR, IGFR, EGFR, cMET, PDGFBetaR, IGF family). The activation of MAPK (mitogen-activated protein kinase), phosphatidylinositol-3-kinase (PI3K-AKT), and the Wnt signaling pathway has also been reported [24].

In a recent study, Melaiu et al. (2012) performed a review and data mining of transcriptome analysis studies published in the literature in order to determine the genes reproducibly deregulated among independent studies [27]. They found a list of genes up- or down-regulated 
in MPM cells, in comparison with normal mesothelial cells. These genes were involved in different pathways. These pathways were related to the regulation of cell proliferation (MAPK and P53 signaling pathways), inflammation (cytokine-cytokine receptor pathway), cell structure and cell dynamics (regulation of actin cytoskeleton) and interaction with extra-cellular components (focal adhesion, ECM-receptor interaction, cell and focal adhesion).

Metabolic pathways are modified in cancer cells in comparison with normal cells. This reprogramming facilitates nutrients uptake and metabolic adaptation to the microenvironment needed for high increase of proliferation rate. MPM cell metabolism has been poorly investigated in comparison with normal mesothelial cells. Characteristics of MPM metabolism shift concern the protein and nucleic acid metabolism, the energetic pathway and the oxidative stress. However, these studies were developed with a limited number of MPM cases and similar studies with a larger number of cases are needed.

A few studies have reported shift of nucleic acid and protein metabolism. Change in the metabolism of adenosine monophosphate was shown by the inactivation of methyladenosine phosphorylase (MTAP), an enzyme regulating the nucleotide synthesis salvage pathway. This inactivation results from the deletion of MTAP gene. This gene co-localized with CDKN2A, a negative regulator of cell proliferation, frequently deleted in MPM A down-regulation, due to epigenetic silencing, of argininosuccinate synthetase (ASS), an enzyme catalyzing a ratelimiting step in the synthesis of arginine has been reported, leading to arginine auxotrophy of MPM cells. In one study, an overexpression of an L-amino acid transporter (LAT1) has been reported, supporting the increased protein synthesis needed for cancer cell growth.

Cancer cells have to adapt to a hypoxic microenvironment from early stages of tumor development. In MPM, changes in energetic metabolism have been suggested by the overexpression of HIF-1alpha, a factor degraded in normoxic conditions. This transcription factor regulates several players of the glycolytic and tricarboxylic acid pathways, and glucose transporters regulating glucose influx such as GLUT-1. GLUT-1 expression is enhanced in MPM in comparison with reactive or normal mesothelial cells. A gene expression profiling has revealed up-regulation of energy pathways reflecting the Warburg effect in mesothelioma cells, and in protein translation and cytoskeletal remodeling pathways (Singhal à citer ?).

Oxidative stress is the cell response to exogenous or endogenous production of oxidants. Cells produce reactive oxygen species (ROS) through multiple mechanisms, including the 
mitochondrial respiratory chain, and cytoplasmic reactions catalyzed by appropriate enzymes; they regulate ROS levels by maintaining the balance between ROS generation, and elimination through anti-oxidant proteins and enzymes. Those are associated with GSH metabolism and its synthesis, and with the regulation of the level of superoxide anion and hydrogen peroxide (GPX, glutathione peroxidase; GR, glutathione reductase; GRX, glutaredoxin and, glutathione; SOD, superoxide dismutase; catalase...). ROS generation may be enhanced in cancer cells in comparison with normal cells. A moderate increase in ROS production can promote cell proliferation and differentiation, whereas excessive amounts of ROS damage the biological molecules, proteins, lipids and DNA. To prevent the deleterious effects of ROS, cancer cells express enhanced levels of anti-oxidant enzymes and anti-oxidant proteins. Adaptation of oxidative stress leads to activation of several redox-sensitive signaling pathways $(\mathrm{NF}-\kappa \mathrm{B}$, cJun, MAPK).

Few data are available on modifications of oxidative stress pathway in MPM, although several studies have investigated the effect of asbestos fibers on the production of ROS in normal mesothelial cells. Some works have studied the expression of enzymes playing a role in antioxidant defense. MPM cells express high level of Mn-SOD, an enzyme located in mitochondria, compared with normal mesothelial cells. Gamma-glutamylcysteine synthetase (GCLC), the rate-limiting enzyme in GSH biosynthesis, was expressed in some MPM but not in healthy mesothelium that was negative for (GCLC). A few other studies have evaluated the genetic variability in anti-oxidant enzymes in MPM and found an increased risk of MPM in patients bearing some specific polymorphic alleles of glutathione-S-transferases (GSTs), manganese superoxide dismutase (MnSOD/SOD2) and glutamyl-S-transferase (GSTM1) genes. However, no definitive data are available.

\section{Biomarkers}

Research of soluble biomarkers in serum, plasma and/or pleural effusions is useful to detect early stages of the disease and its evolution, and to discriminate between mesothelioma effusions from other malignant and benign effusions. Several markers have been studied: mesothelin, a protein expressed at the surface of mesothelial cells of the pleura; megacaryocyte potentiating factor, a fragment resulting from the processing of mesothelin; osteopontin, a glycoprotein expressed on the cell membrane of different cell types; and, more recently, fibulin3 , an extracellular glycoprotein of the fibulin family. Future validation studies should continue to establish the relevance of these markers. Immunohistochemical biomarkers are used for mesothelioma diagnosis. Consensus guidelines have recently been published [21]. In addition 
to these traditional biomarkers, circulating cells should be taken into account and the detection of these cells in blood samples may be interesting for diagnosis and therapeutic purposes.[28]. Biomarkers are useful for translational research, but provide little information about the transformation mechanism of mesothelial cells.

\section{Origin of MPM cells}

The origin of the mesothelial cell population that initiates tumor development remains unknown. It can occur because of the regeneration of mesothelium due to mesothelial cell turnover or repair of damaged mesothelium. A proliferation of mesothelial cells with persistent and inheritable damage can be assumed. Mutsaers et al. (2002) have suggested different mechanisms of mesothelium repair: centripetal migration of mesothelial cells, proliferation of adjacent cells, macrophage transformation, attachment of free-floating cells present in the pleural cavity, submesothelial precursors (migration of submesothelial mesenchymal precursors), and bone-marrow-derived circulating precursors [29]. It is likely that the mechanism depends on the type and gravity of damage.

It can be noted that the morphology of mesothelial cells is not unique along the pleura. Flat mesothelial cells are most frequent, but some areas contain cuboidal cells, attesting to a heterogeneity that may be linked to different functions [29]. To our knowledge, their specificities remain unknown.

The existence of a side cell population has been detected in mesothelioma. It could include cancer stem cells (CSC), a subpopulation of malignant cells capable of self-renewal and multilineage differentiation. While this concept is still being debated, features of CSC cells have been described in MPM, but their relevance to MPM development will require further investigation [30].

\section{Mechanism of neoplastic mesothelial cell transformation}

The different steps inducing the neoplastic transformation of mesothelial cells and the physiological events leading to the development of MPM are not fully understood, but some hypotheses can be suggested. Several cellular and molecular effects observed in mesothelial cells after exposure to the major risk factor, asbestos, and changes in gene integrity or pathway regulation described in MPM may possibly be involved in carcinogenesis [31] (Figure 3).

Neoplastic transformation is a multistep process. Hanahan et al. (2012) recently reviewed the hallmarks of cancer, defining the six acquired biological capabilities of the cells during transformation [31]. They were: (1) sustained proliferation, which can be acquired by autocrine 
or paracrine growth, or deregulated growth signaling. Several growth factors and receptor pathways seem to be activated in MPM, including HGF/cMET and EGF/EGFR, and VEGF and IGF pathways and PDGGBeta/PDGFBetaR[1]; (2) insensitivity to anti-growth signals is another criteria. It is known that the loss of cell cycle regulators such as P15 $5^{\mathrm{INK} 4 \mathrm{~B}}$ and P16 ${ }^{\mathrm{INK} 4 \mathrm{~A}}$ lead to escape from control of proliferation; (3) evading apoptosis that facilitates sustained growth. In MPM apoptosis may result in several alterations of the extrinsic and intrinsic pathways [1, 24]; (4) immortality. Loss of senescence has not been investigated in mesothelial cells; (5) induction of angiogenesis that may be associated with the overproduction of VEGF [24]; and (6) tissue invasion. This mechanism has not been well investigated in MPM. However, MPM is characterized by a local invasion of the pleural muscle and adipose tissues, attesting to the invasive potential of mesothelioma cells. Moreover, transcriptomic analyses in MPM revealed deregulation of pathways involved in adherence and interaction with the extracellular matrix [27]. In addition, neoplastic changes modify the relationships with the microenvironment, which facilitates tumor cell growth.

Several phenotypical criteria, based on morphology and genomics, have been identified as characteristics of transformed cells. They are related to one or more of the hallmarks. MPM cells express some of these features as shown in Table 1. In addition, the differential regulations of metabolic pathways that may account for the neoplastic features of MPM cells are summarized in this Table.

Among the genes inactivated in MPM, several can play a role in the acquisition of these capabilities. NF2 is involved in several mechanisms (cell proliferation, maintenance of cell junctions). Its mutation does not seem to be an initiating event in mesothelial cell transformation, based on the investigation of genetically-modified mouse models of mesothelioma [32]. However, lack of functional NF2 can restrain control of cell proliferation and modify cell-cell interactions, facilitating cell growth, motility and migration. Recent studies have suggested that NF2 protein could also localize in the nucleus and inhibit a nuclear ubiquitin ligase complex involved in the regulation of a specific gene expression program. It is interesting to observe that loss of $N F 2$ should consequently favor nuclear ubiquitination of specific proteins, the same consequence as the loss of the BAPl gene, which encoded a nuclear deubiquitinase. On the basis of these findings, it is possible to illustrate a schematic mechanism of MPM development (Figure 3). 
Several concepts have been suggested to explain the mechanism of carcinogenesis. Genomes of cancer cells exhibit a number of mutations, supporting the notion that cancers express a "mutator phenotype" [33]. This can result from the occurrence of mutations in genes controlling DNA integrity, leading to amplification of mutations. Independently of DNA damage and mutations, numerical (aneuploidy) and structural chromosome alterations can strongly modify the gene copy number of relevant oncogenes and tumor suppressor genes in mesothelial cells [34]. Chromosome aneuploidy can be generated by abnormal mitosis, including chromosome missegregation, atypical mitotic spindle assembly, supernumerary centrosomes, and a defective spindle assembly checkpoint [34]. Several recent studies reported that abnormal mitosis alone is sufficient to generate DNA damage. All of these effects have been observed in mesothelial cells exposed to asbestos fibers (see section on lung and pleural cell responses to asbestos fibers). These findings make it possible to suggest a mechanism whereby asbestos fibers play a role in MPM development and the evolution of neoplastic mesothelial cell transformation (Figure 3).

\section{References}

1. Rascoe PA, Jupiter D, Cao X, Littlejohn JE, Smythe WR: Molecular pathogenesis of malignant mesothelioma. Expert Rev Mol Med 2012, 14:e12.

2. Huang SX, Jaurand MC, Kamp DW, Whysner J, Hei TK: Role of mutagenicity in asbestos fiber-induced carcinogenicity and other diseases. $J$ Toxicol Environ Health B Crit Rev 2011, 14(1-4):179-245.

3. Kamp DW: Asbestos-induced lung diseases: an update. Transl Res 2009, 153(4):143152.

4. Pairon JC, Laurent F, Rinaldo M, Clin B, Andujar P, Ameille J, Brochard P, Chammings S, Ferretti G, Galateau-Salle $\mathrm{F}$ et al: Pleural plaques and the risk of pleural mesothelioma. J Natl Cancer Inst 2013, 105(4):293-301.

5. Carbone M, Baris YI, Bertino P, Brass B, Cornertpay S, Dogan A, Gaudino G, Jube S, Kanodia S, Partridge CR et al: Erionite exposure in North Dakota and Turkish villages with mesothelioma Proc Natl Acad Sci U S A 2011, 108.

6. Lacourt A, Gramond C, Audignon S, Ducamp S, Fevotte J, Gilg Soit Ilg A, Goldberg M, Imbernon E, Brochard P: Pleural Mesothelioma and Occupational Co-exposure to Asbestos, Mineral Wool and Silica. Am J Respir Crit Care Med 2013.

7. Pintos J, Parent ME, Case BW, Rousseau MC, Siemiatycki J: Risk of mesothelioma and occupational exposure to asbestos and man-made vitreous fibers: evidence 
from two case-control studies in Montreal, Canada. J Occup Environ Med 2009, 51(10):1177-1184.

8. Jaurand MC, Renier A, Daubriac J: Mesothelioma: Do asbestos and carbon nanotubes pose the same health risk? Part Fibre Toxicol 2009, 6:16-29.

9. Jasani B, Gibbs A: Mesothelioma not associated with asbestos exposure. Arch Pathol Lab Med 2012, 136(3):262-267.

10. Gibb H, Fulcher K, Nagarajan S, McCord S, Fallahian NA, Hoffman HJ, Haver C, Tolmachev S: Analyses of Radiation and Mesothelioma in the US Transuranium and Uranium Registries. Am J Public Health 2013, 103(4):710-716.

11. Neri M, Filiberti R, Taioli E, Garte S, Paracchini V, Bolognesi C, Canessa PA, Fontana V, Ivaldi GP, Verna A et al: Pleural malignant mesothelioma, genetic susceptibility and asbestos exposure. In: Mutat Res. 2005.

12. Broaddus VC, Everitt JI, Black B, Kane AB: Non-neoplastic and neoplastic pleural endpoints following fiber exposure. J Toxicol Environ Health B Crit Rev 2011, 14(14):153-178.

13. Shukla A, Ramos-Nino M, Mossman B: Cell signaling and transcription factor activation by asbestos in lung injury and disease. Intl J Biochem Cell Biol 2003, 35:1198-1209.

14. Dostert C, Petrilli V, Van Bruggen R, Steele C, Mossman BT, Tschopp J: Innate immune activation through Nalp3 inflammasome sensing of asbestos and silica. Science 2008, 320(5876):674-677.

15. Chow MT, Tschopp J, Moller A, Smyth MJ: NLRP3 promotes inflammation-induced skin cancer but is dispensable for asbestos-induced mesothelioma. Immunol Cell Biol 2012, 90(10):983-986.

16. Cortez B, Quassollo G, Caceres A, Machado-Santelli GM: The fate of chrysotileinduced multipolar mitosis and aneuploid population in cultured lung cancer cells. PLoS ONE 2011, 6(4):e18600.

17. Carbone M, Ly BH, Dodson RF, Pagano I, Morris PT, Dogan UA, Gazdar AF, Pass HI, Yang H: Malignant mesothelioma: facts, myths, and hypotheses. J Cell Physiol 2012, 227(1):44-58.

18. Dong HY, Buard A, Levy F, Renier A, Laval F, Jaurand MC: Synthesis of poly(ADPribose) in asbestos treated rat pleural mesothelial cells in culture. Mutat Res 1995, 331:197-204.

19. Upadhyay D, Kamp DW: Asbestos-induced pulmonary toxicity: role of DNA damage and apoptosis. Exp Biol Med (Maywood) 2003, 228(6):650-659.

20. Tomasetti M, Amati M, Nocchi L, Saccucci F, Strafella E, Staffolani S, Tarquini LM, Carbonari D, Alleva R, Borghi B et al: Asbestos exposure affects poly(ADP-ribose) polymerase-1 activity: role in asbestos-induced carcinogenesis. Mutagenesis 2011, 26(5):585-591.

21. Churg A, Galateau-Salle F: The separation of benign and malignant mesothelial proliferations. Arch Pathol Lab Med 2012, 136(10):1217-1226.

22. Relan V, Morrison L, Parsonson K, Clarke BE, Duhig EE, Windsor MN, Matar KS, Naidoo R, Passmore L, McCaul E et al: Phenotypes and karyotypes of human malignant mesothelioma cell lines. PLoS One 2013, 8(3):e58132.

23. Matsumoto S, Nabeshima K, Kamei T, Hiroshima K, Kawahara K, Hata S, Marukawa K, Matsuno Y, Taguchi K, Tsujimura T: Morphology of 9p21 homozygous deletionpositive pleural mesothelioma cells analyzed using fluorescence in situ hybridization and virtual microscope system in effusion cytology. Cancer Cytopathol 2013. 
24. Jean D, Daubriac J, Le Pimpec-Barthes F, Galateau-Salle F, Jaurand MC: Molecular changes in mesothelioma with an impact on prognosis and treatment. Arch Pathol Lab Med 2012, 136(3):277-293.

25. Tallet A, Nault JC, Renier A, Hysi I, Galateau-Salle F, Cazes A, Copin MC, Hofman P, Andujar $\mathrm{P}$, Le Pimpec-Barthes $\mathrm{F}$ et al: Overexpression and promoter mutation of the TERT gene in malignant pleural mesothelioma. Oncogene 2014, 33(28):3748-3752.

26. Balatti V, Maniero S, Ferracin M, Veronese A, Negrini M, Ferrocci G, Martini F, Tognon MG: MicroRNAs dysregulation in human malignant pleural mesothelioma. J Thorac Oncol 2011, 6(5):844-851.

27. Melaiu O, Cristaudo A, Melissari E, Di Russo M, Bonotti A, Bruno R, Foddis R, Gemignani F, Pellegrini S, Landi S: A review of transcriptome studies combined with data mining reveals novel potential markers of malignant pleural mesothelioma. Mutat Res 2012, 750(2):132-140.

28. Pinton G, Manente AG, Moro L, Mutti L: Circulating tumor cells as a diagnostic test for malignant pleural mesothelioma. Expert Opin Med Diagn 2013, 6(3):171-173.

29. Mutsaers SE: Mesothelial cells: their structure, function and role in serosal repair. Respirology 2002, 7(3):171-191.

30. Ghani FI, Yamazaki H, Iwata S, Okamoto T, Aoe K, Okabe K, Mimura Y, Fujimoto N, Kishimoto T, Yamada $\mathrm{T}$ et al: Identification of cancer stem cell markers in human malignant mesothelioma cells. Biochem Biophys Res Commun 2011, 404(2):735-742.

31. Hanahan D, Weinberg RA: Hallmarks of cancer: the next generation. Cell 2012, 144(5):646-674.

32. Fleury-Feith J, Lecomte C, Renier A, Matrat M, Kheuang L, Abramowski V, Levy F, Janin A, Giovannini M, Jaurand MC: Hemizygosity of $\mathbf{N f 2}$ is associated with increased susceptibility to asbestos-induced peritoneal tumours. Oncogene 2003, 22:3799-3805.

33. Loeb LA: Human cancers express mutator phenotypes: origin, consequences and targeting. Nat Rev Cancer 2011, 11(6):450-457.

34. Ganem NJ, Pellman D: Linking abnormal mitosis to the acquisition of DNA damage. J Cell Biol 2012, 199(6):871-881. 
Figure 1: Classification of fibers.

Schematic representation of the main groups and types of fibers of interest to human health issues. Organic fibers have different chemical compositions. CNTs consist of carbon and SVFs are amorphous fibers made of silica and different compositions of alkali and alkaline-earth cations. RCFs also contain aluminum and some metals. Natural fibers are silicates with different chemical compositions:

Erionite $\left[\mathrm{CaKMg}\left(\mathrm{Al}_{5} \mathrm{Si}_{13} \mathrm{O}_{36}\right) 16 \mathrm{H}_{2} \mathrm{O}\right] ;$ crocidolite $\left[\left(\mathrm{Si}_{8} \mathrm{O}_{22}\right)(\mathrm{OH})_{2}\left(\mathrm{MgFe}^{2+}\right)\right] ;$ amosite $\left[\left(\mathrm{Si}_{8} \mathrm{O}_{22}\right)(\mathrm{OH})_{2} \mathrm{Na}_{2}\left(\mathrm{Fe}^{2+}\right)_{3} \quad\left(\mathrm{Fe}^{3+}\right)_{2}\right] ;$ tremolite $\quad\left[\left(\mathrm{Ca}_{2} \mathrm{Mg}_{5}\right)\left(\mathrm{Si}_{8} \mathrm{O}_{22} \quad(\mathrm{OH})_{2}\right] ; \quad\right.$ chrysotile $\left[\mathrm{Mg}_{3}\left(\mathrm{Si}_{2} \mathrm{O}_{5}\right)(\mathrm{OH})_{4}\right]$.

Abbreviations: CNTs: carbon nanotubes; RCFs: refractory ceramic fibers; SVFs: synthetic vitreous fibers.

Figure 2: Schematic representation of different steps possibly involved after asbestos translocation in the pleura.

Fibers can be translocated to the pleural space where they can be drained via the parietal lymphatics or interact with mesothelial cells. Fiber uptake, induction of inflammatory reaction and the physico-chemical properties of asbestos can lead to DNA damage.

Repair processes can occur, with restitution of mesothelial cells to their normal state. However, DNA repair may be error-prone, leaving damaged cells able to generate daughter cells with inherited damage, as well as gene mutations. Due to normal turnover, inflammatory-induced growth stimulation and repair of the mesothelial cell sheet, abnormal mitoses can lead to chromosome abnormalities and generate chromosome instability in proliferating mesothelial cells.

After several generations of mesothelial cells, genomic instability can lead over time to neoplastic transformation and tumor growth facilitated by modifications of the cellular and molecular microenvironment.

Figure 3: Hypotheses on mechanisms that lead to neoplastic transformation of mesothelial cells.

Basic events consist of gene and cellular alterations provoked by carcinogenic agents such as asbestos fibers, which are then inherited by subsequent cell generations because of damage misrepair.

Several mutated genes have been identified in MPM. They encode proteins involved in regulatory functions of cell growth, cell-cell interactions, protein stability and chromatin remodeling. Other regulations of these proteins are still unknown. Both gene mutations and abnormal gene expression (level or timing) lead to failed cell homeostasis and interactions with extra-cellular milieu. Finally, alterations of key functions of mesothelial cells make it possible to acquire the features of cancer cells and the hallmarks of carcinogenesis. This is a very incomplete mechanism. Further studies will provide data on the kinetics and events that occur during the initiation and progression steps of mesothelial cell transformation. 
Table 1: MPM cells phenotype: Morphological, genetic and metabolic features of MPM cells compared to classical features of transformed cells

\begin{tabular}{|c|c|c|c|}
\hline Normal cells & Transformed cells & $\begin{array}{l}\text { Criteria found in MPM } \\
\text { cells? }\end{array}$ & $\begin{array}{l}\text { Relevant } \\
\text { hallmarks }\end{array}$ \\
\hline \multicolumn{4}{|l|}{ Growth } \\
\hline Contact inhibition & Loss of contact inhibition & Yes & $1,2,3,4$ \\
\hline Controlled growth & Loss of cell growth control & Yes & $1,2,3,4$ \\
\hline $\begin{array}{l}\text { GF-dependent } \\
\text { proliferation }\end{array}$ & $\begin{array}{l}\text { GF-independent } \\
\text { proliferation (autocrine } \\
\text { growth) }\end{array}$ & $\begin{array}{l}\text { MPM cells express several } \\
\text { growth factors and } \\
\text { corresponding receptors }\end{array}$ & $1,2,3,5$ \\
\hline $\begin{array}{l}\text { No growth in semi-solid } \\
\text { medium }\end{array}$ & $\begin{array}{l}\text { Growth in semi-solid } \\
\text { medium }\end{array}$ & Yes but not systematic* & $1,2,3$ \\
\hline $\begin{array}{l}\text { Tumor growth in nude } \\
\text { mice }\end{array}$ & $\begin{array}{l}\text { Absence of tumorigenicity } \\
\text { in nude mice }\end{array}$ & Yes but not systematic & Several \\
\hline \multicolumn{4}{|l|}{ Genomics } \\
\hline Normal karyotype & $\begin{array}{l}\text { Chromosomal } \\
\text { abnormalities }\end{array}$ & Yes & Several \\
\hline Normal genes & $\begin{array}{l}\text { Oncogene activation } \\
\text { Tumor suppressor genes } \\
\text { inactivation }\end{array}$ & $\begin{array}{l}\text { Yes } \\
\text { Yes, several }\end{array}$ & Several \\
\hline \multicolumn{4}{|l|}{$\begin{array}{l}\text { Metabolic } \\
\text { reprogrammingt }\end{array}$} \\
\hline Protein metabolism & $\begin{array}{l}\text { Disruption of cell } \\
\text { homeostasis }\end{array}$ & $\begin{array}{l}\text { Arginine auxotrophy } \\
\text { Enhanced expression of } \\
\text { LAT1 }\end{array}$ & Several \\
\hline $\begin{array}{l}\text { Altered glucose } \\
\text { metabolism }\end{array}$ & $\begin{array}{l}\text { Warburg effect (aerobic } \\
\text { glycolysis) }\end{array}$ & $\begin{array}{l}\text { Enhanced expression of } \\
\text { GLUT-1 } \\
\text { Down-regulation of ASS }\end{array}$ & Several \\
\hline $\begin{array}{l}\text { Response to oxidative } \\
\text { stress }\end{array}$ & $\begin{array}{l}\text { Disruption of redox } \\
\text { homeostasis }\end{array}$ & $\begin{array}{l}\text { Overexpression of MnSOD } \\
\text { Expression of gamma GCS }\end{array}$ & Several \\
\hline
\end{tabular}

* MPM cells can also form spheroids when cultured in non-adherent conditions, in agreement with anchorage-independent growth. In these conditions, MPM cells are resistant to anoïkis.

GF: Growth factor; PerM: Malignant Peritoneal Mesothelioma

Several: Several hallmarks can be concerned. Genomic changes may have impact depending on the gene(s) altered, and the consequences of metabolic reprogramming will depend on the homeostatic function of the pathway. These changes will also modify the relationship with the cell microenvironnement. 


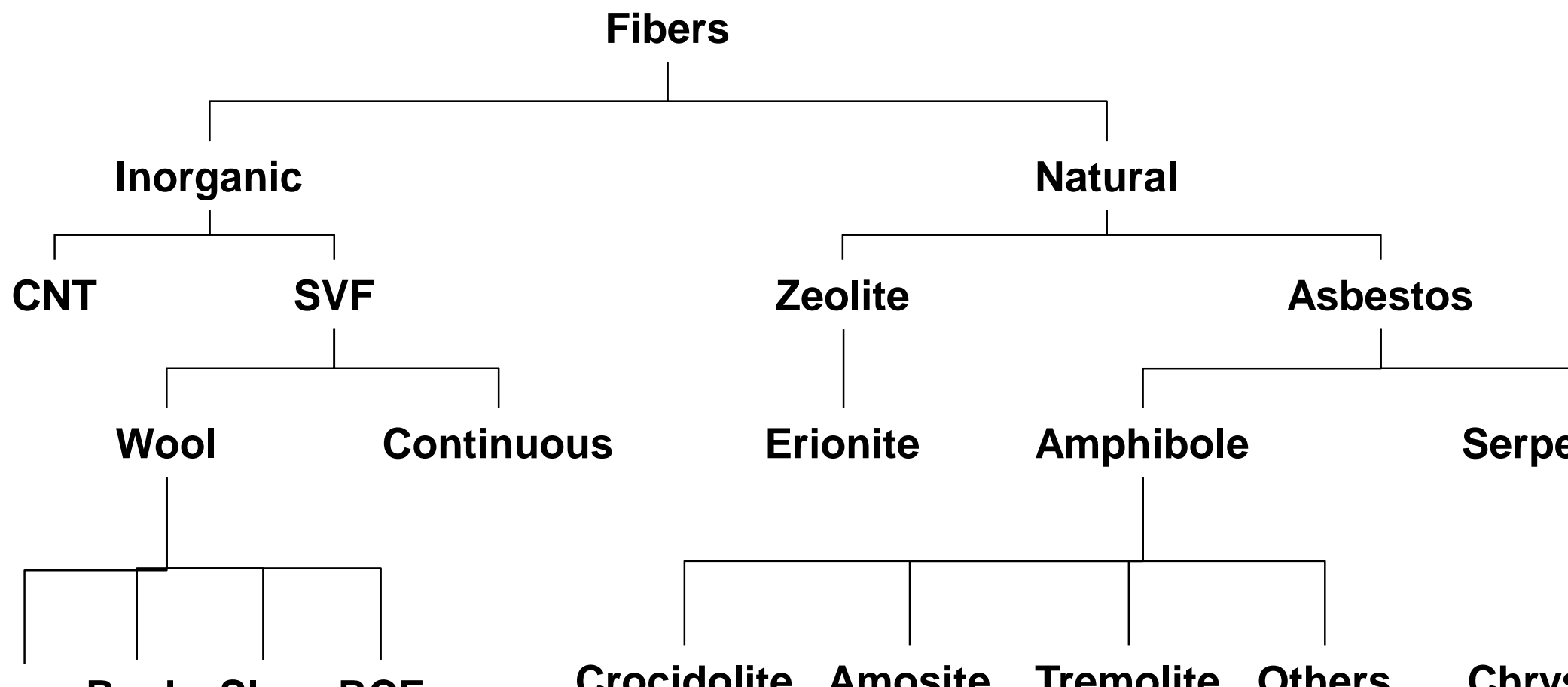

Glass Rock Slag RCF

Crocidolite Amosite Tremolite Others Chrysotile 


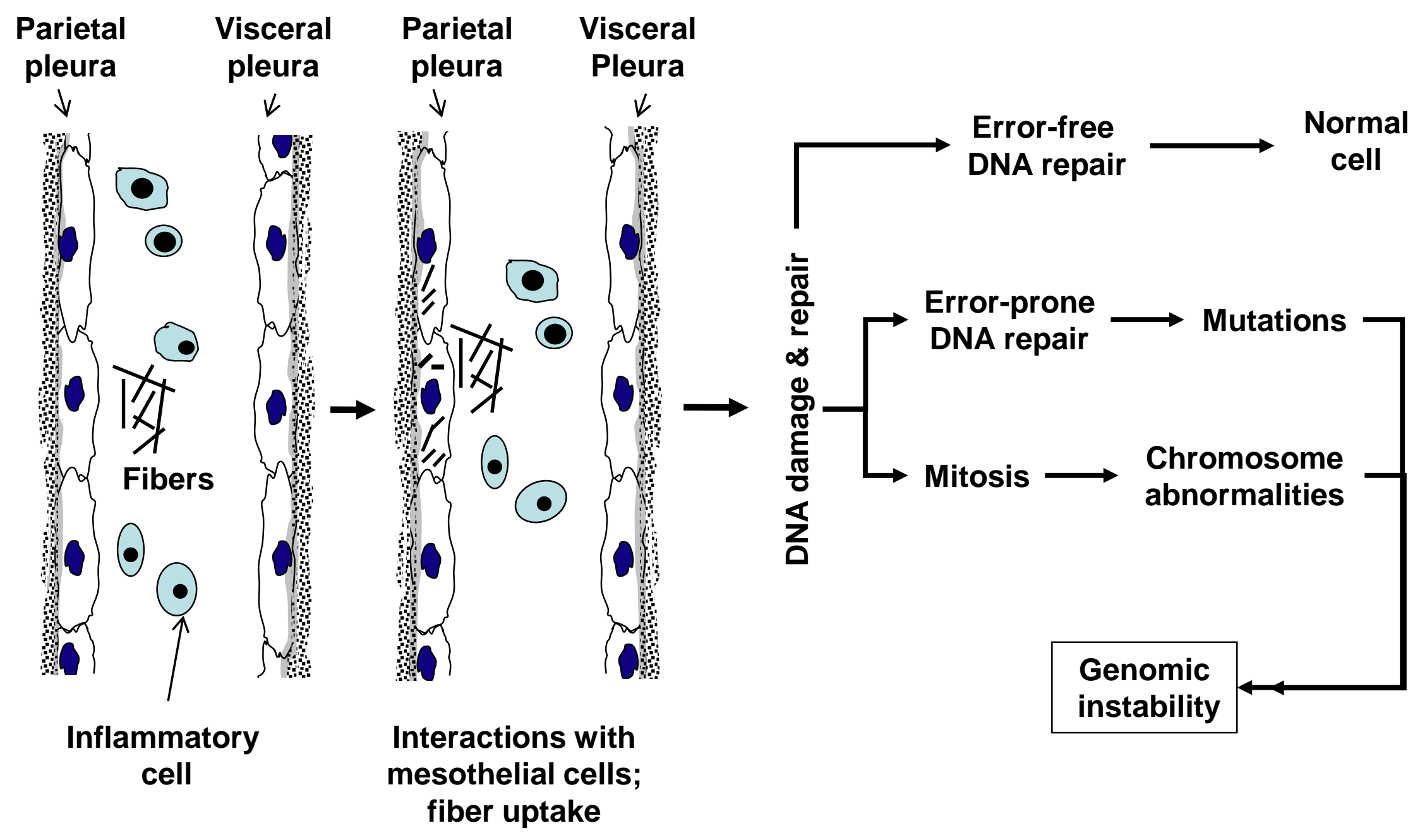




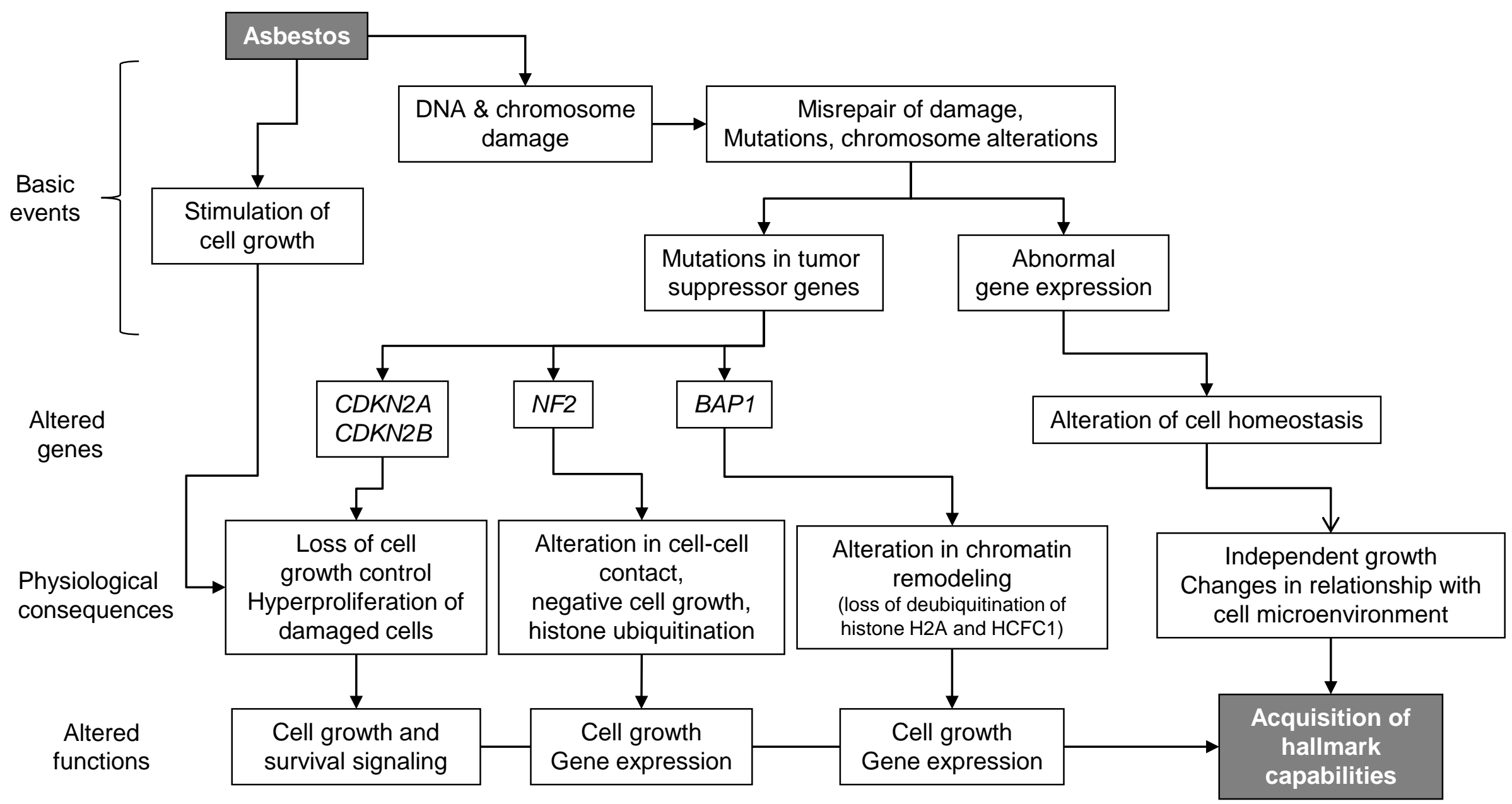

